\title{
Dr. Richard C. Nelson: The Founding Father of Biomechanics
}

\author{
Vladimir Zatsiorsky \\ The Pennsylvania State University
}

\begin{abstract}
Recollections on meetings with Dick Nelson in the 1970s, his interactions with Soviet authorities, his impact on data collection at Olympic Games, and his work as the President of the International Society of Biomechanics.
\end{abstract}

Keywords: International Society of Biomechanics, Soviet scientists, Olympic Games

I met Dick Nelson for the first time at the third international Seminar of Biomechanics in Rome in 1971, exactly 50 years ago. It was my first international conference. I did not know anybody personally, and I wanted to know who was who. So I enjoyed myself by associating with the people around me, mainly the conference speakers who had written publications known to me.

This was not always possible; many speakers either had not published anything yet, or I did not know what exactly they had published. But I recognized Dick instantly. Quite recently I had read his paper (in coauthorship with Chuck Dillman) in which they studied pole vaulting and compared the kinetic energy of the athlete's body during running immediately prior to takeoff with the potential energy of his body at the apex of the jump. ${ }^{1}$ The issue at hand was whether the athlete loses or increases mechanical energy during the work on the pole, and the immediate motivation for the study was introducing new, at that time, fiberglass poles. Despite some limitations of the study (e.g. body rotational energy was neglected), I liked it and appreciated the work done.

Also, almost immediately before departure to the conference, I read his recent paper (in coauthorship with Jiri Sukop, whom I met previously in Prague) in which the authors proudly reported that they electronically recorded force signals and used an analogto-digital converter to feed the data into a digital computer. ${ }^{2}$ At that time, such a technical achievement warranted a publication in a scientific journal, The Research Quarterly. Such was the technical level of sports biomechanics research at that time.

So, I respected Dr. Nelson as a serious biomechanical researcher.

The next time we met was 2 years later during the fourth international Seminar of Biomechanics, which Dick and Chauncey (Dewey) Morehouse hosted in State College, Pennsylvania (August 26-August 31, 1973). Conference participants were invited to visit the Biomechanics Lab that was located at the old water tower nearby. This was a watershed experience. By the standards of that time, the laboratory was fantastically wellequipped. It had everything that a biomechanics researcher could dream of. High-speed 16-mm Locam cine cameras, cine analyzer to measure not only linear but also angular coordinates, Kistler force plates-everything. Even more, the laboratory had its own PDP-11 computer.

At that time, to perform computations (mainly statistics), we had to go to a special computer center, manually type our data on

Zatsiorsky is with the Department of Kinesiology, The Pennsylvania State University, University Park, PA, USA. punch cards, sign in advance for a computer time, and only then perform the computations. And here they had a computer, right at the lab. For us, the lab looked absolutely fantastic. I think that in 1973 it was the only lab in the world that was so brilliantly equipped.

There was also a group of young talented researchers, either graduate students or recent postgraduates, among them Chuck Dillman and Doris Miller, and above all an enthusiastic and recent-Ph.D. Peter Cavanagh, who generated a ton of new ideas and impressed us with his computer skills, which was quite unusual for biomechanics researchers at that time.

During the conference, the International Society of Biomechanics (ISB) was established. That same year, 1973, a book by Doris Miller and Richard Nelson, Biomechanics of Sport, was published. ${ }^{3}$

We returned back to Moscow with the feeling that biomechanics of human motion, in particular the biomechanics of sport, was from then on an established scientific discipline, and the biomechanics lab at Penn State under Dr. Richard C. Nelson was its leading research institution.

In 1977, Dick was elected the ISB President. As the President, he did a marvelous job. He was a champion of 2 ideas:

First, he tried to increase ISB membership, particularly by increasing the number of countries whose researchers joined the society. There were 2 problems that made this task difficult. First, in many countries, there were no biomechanics researchers at all and a very limited understanding of this scientific discipline. Biomechanics-what is it? Second, there were problems with the so-called "socialist" countries. Some of them, like for instance the Soviet Union, were very rigid and had strange regulations that limited the opportunities for scientists to join the Society. For instance, Soviet scientists were not allowed to join international scientific societies, not only the ISB but all societies, as individuals. Only collective membership was permitted.

As the ISB president, Dick traveled a lot around the globe, delivering lectures, and explaining what biomechanics is and how biomechanical research is conducted. In particular, he told me that he was the first American scientist who visited China after the death of Mao Zedong (1976). When in 1979 I had a lucky chance to stop at Dick's lab, I met there one Chinese professor (sorry, I forgot his name), who during the "cultural revolution" was purged and sent to the countryside for hard manual labor. Dick covered all expenses associated with his travel and stay in the United States.

Second, Dick was a great enthusiast of performing biomechanical filming at Olympic competitions. The initial impetus for this project arose after the 1968 Olympic Games, at which Bob 
Beamon set a new world record in long jumping. His performance, $890 \mathrm{~cm}-55 \mathrm{~cm}$ above the existing record!-was absolutely astonishing. And this historic jump was not properly recorded. The only available film was of bad quality, with a human figure overlapping part of the jump. Dick's idea was that such feats in the future should be properly documented-for history and biomechanical analysis. Dick remained a great devotee of Olympic biomechanics filming for a long time and once, when the International Olympic Committee refused to support this project financially, Dick bankrolled it himself.

In 1980, the next Olympic Games were planned in Moscow. However, in December 1979, Soviet troops invaded Afghanistan and the US government decided to boycott these Games. Earlier in the summer of that year, the preparation for the Games was in full swing, and Dick and a small American group arrived at Moscow to prepare for the filming, for example, to select places for the cameras and the crews and obtain the necessary permissions from the authorities. To finalize the deal, he was accepted by the Vice Chairman of the Union of Soviet Socialist Republics (USSR) Sports Committee, essentially a Deputy Minister of Sport.

I was present at the meeting. During the meeting, Dick also raised a question on the membership of the Soviet scientists in the ISB. As I already mentioned, the Soviet scientists were not allowed to personally join international societies; only collective memberships by national societies were allowed. But at this time, the AllUnion Society of Biomechanics, or Sport Biomechanics, did not exist, so for the Soviet biomechanics to join the ISB, some issues had to be resolved. Firstly, a National Society had to be established, and secondly, this Society had to apply to the ISB for the collective membership.

I was surprised how quickly Dick had grasped this unusual (for an American scientist) situation and how skillfully and diplomatically he discussed the issues. He understood the psychology of this
Soviet bureaucrat, and he mastered speaking his language. Dick evidently had a talent that suits a professional diplomat. $\mathrm{He}$ managed to persuade this party boss that joining the ISB was advantageous for Soviet science. Our previous attempts to do that miserably failed. I do not remember the details, but after this talk, Soviet scientists were able to take part in ISB activities. Indeed Dick was a very good ISB President.

Among Soviet researchers, there was a shared opinion that Dick Nelson was a leading person in biomechanics and that his lab was the embodiment of the contemporary biomechanics lab. For biomechanists visiting the United States, Penn State played the role of a central hub, and all travels included visiting it. When in 1990 I was invited as a visiting professor by University of California at Los Angeles (UCLA) and the University of Calgary, stopping over in State College was not in my plans. Dick however arranged to meet me at the John F. Kennedy International airport. We drove down to State College where I stayed several nights at the university hotel, and only after that did I fly to LA. The custom was preserved.

During the early period of biomechanics development, 19651995, Dick's contribution to this field was outstanding.

\section{References}

1. Dillman CJ, Nelson RC. The mechanical energy transformations of pole vaulting with a fiberglass pole. J Biomech. 1968;1(3):175-183. doi:10.1016/0021-9290(68)90002-X

2. Sukop J, Petak KL, Nelson RC. An on-line computer system for recording biomechanical data. Res $Q, 1971 ; 42(1): 101-102$. doi:10. 1080/10671188.1971.10615043

3. Miller DI, Nelson RC. Biomechanics of Sport. London, UK: Henry Kimpton; 1973. 